\title{
CBX3 predicts an unfavorable prognosis and promotes tumorigenesis in osteosarcoma
}

\author{
CHAO MA $^{1^{*}}$, XING-GUO NIE $^{1^{*}}$, YAN-LI WANG ${ }^{2 *}$, XIANG-HUA LIU ${ }^{1}$, \\ XUE LIANG ${ }^{3}$, QING-LAN ZHOU ${ }^{1}$ and DA-PENG WU ${ }^{1}$ \\ Departments of ${ }^{1}$ Orthopedics, ${ }^{2}$ Operating Theatre and ${ }^{3}$ Central Sterile Supply, \\ The First Affiliated Hospital of Xinxiang Medical University, Xinxiang, Henan 453000, P.R. China
}

Received August 14, 2018; Accepted March 7, 2019

DOI: $10.3892 / \mathrm{mmr} .2019 .10104$

\begin{abstract}
CBX3, namely chromobox protein homolog 3, a member of the heterochomatin protein 1 (HP1) family, has been shown to be associated with the tumorigenesis of various types of cancer. The aim of the present study was to assess the biological role and the clinicopathological importance of CBX3 in osteosarcoma. The Oncomine database was utilized to determine the CBX3 expression in sarcoma patients. A retrospective cohort study was conducted to evaluate the prognostic value of CBX3 expression. In addition, correlations between the clinicopathological features of the osteosarcoma patients and CBX3 expression were assessed and involved recurrence, distant metastasis, lymph node metastasis, response to chemotherapy, pathological differentiation, clinical stage, anatomic location, tumor size and age. To investigate the function of $\mathrm{CBX} 3$ in osteosarcoma, a small interfering RNA for $\mathrm{CBX} 3$ was designed and this was used for the transfection of osteosarcoma MG63 cells. Then, the effects of CBX3 on proliferation, cell cycle distribution and apoptosis of osteosarcoma cells were investigated via CCK- 8 assay and cell cycle assay and cell apoptosis analysis, respectively. Based on our findings, upregulation of $\mathrm{CBX} 3$ expression was noted both in
\end{abstract}

Correspondence to: Dr Da-Peng Wu, Department of Orthopedics, The First Affiliated Hospital of Xinxiang Medical University, 88 Jiankang Road, Xinxiang, Henan 453000, P.R. China

E-mail: wudapeng2016@163.com

*Contributed equally

Abbreviations: CBX3, chromobox protein homolog 3; HP1, heterochromatin protein 1; DMEM, Dulbecco's modified Eagle's medium; NBT, normal brain tissue; siRNA, small interfering RNA; qPCR, quantitative polymerase chain reaction; GAPDH, glyceraldehyde-3-phosphate dehydrogenase; CCK-8, Cell-Counting Kit-8; PBS, phosphate-buffered saline; OS, overall survival; DFS, disease-free survival; H3K9, methyl groups of histone H3 at lysine 9; HP1 $\gamma$, heterochromatin protein $1 \gamma$

Key words: CBX3, osteosarcoma, clinicopathological, prognosis, proliferation osteosarcoma and also other sarcoma types, which included pleomorphic liposarcoma, myxofibrosarcoma, myxoid/round cell liposarcoma and dedifferentiated liposarcoma. In addition, based on the retrospective cohort study, CBX3 expression was associated with the disease-free survival (DFS) and overall survival (OS) of the osteosarcoma patients and a large tumor size, high distant metastasis rate and high clinical stage rate. In addition, the proliferation ability was blocked by the knockdown of CBX3 through the application of CBX3 siRNA, and CBX3 knockdown also led to increased apoptosis and cell cycle arrest at G0 and G1 phases in osteosarcoma cells. CBX3 is highly expressed in human osteosarcoma tissues. Meanwhile, high CBX3 is a predictor of the poor prognosis of osteosarcoma patients. To conclude, the growth of osteosarcoma can be promoted by CBX3, which may be used as an independent potential prognostic biomarker for patients suffering from osteosarcoma.

\section{Introduction}

Osteosarcoma is the most commonly diagnosed primary malignant bone tumor, and can lead to tumor-related mortality among children and adolescents (1). Osteosarcoma is the most common form of bone and soft tissue malignant tumor, and is characterized by high tumor cell proliferation, high mortality and rapid metastasis (2). Unfortunately, the prognosis of patients with metastatic osteosarcoma remains poor (3). In addition, only a slight improvement in the survival rate of osteosarcoma patients has been achieved even following the development of novel therapeutic technologies, such as radiotherapy, adjuvant chemotherapy and surgery $(4,5)$. To date, there are few available biomarkers to manage the tumor burden and also the treatment response for osteosarcoma. Thus, prognostic assessment and early diagnosis of osteosarcoma are of great importance. Therefore, the prognostic evaluation and early diagnosis of osteosarcoma are important for the initiation of early treatment and thus patient survival can be improved accordingly.

Chromobox protein homolog 3 (CBX3) belongs to the heterochomatin protein 1 (HP1) family, which is involved in transcriptional activation or repression, cell differentiation and growth and epigenetic modifications $(6,7)$. Additionally, it has been reported that $\mathrm{CBX} 3$ is upregulated in many cancer types, 
which is of great significance for the development of cancer and the regulation of growth-related genes $(8,9)$. Thus, it is expected that $\mathrm{CBX} 3$ plays an extremely significant role in the progression of tumors. However, the functional role of $\mathrm{CBX} 3$ in osteosarcoma progression, tumorigenesis and prognosis requires further elucidation.

The present study is the first to investigate the functional role and prognostic value of CBX3 in osteosarcoma. This study demonstrated that there was a high expression of CBX3 in sarcoma and osteosarcoma tissues. In addition, the clinical significance of CBX3 expression in human osteosarcoma was also explored. Meanwhile, the impact of CBX3 on cell cycle distribution, apoptosis and proliferation of osteosarcoma cells was also investigated.

\section{Materials and methods}

Bioinformatic analysis through Oncomine databases. Oncomine database (https://www.oncomine.org) was used for the assessment of the differences in CBX3 mRNA expression between matched normal tissues and sarcoma tissues, based on the following filtering conditions: P-value $<0.0001$, gene rank (top 10\%), fold change $>2$, data type (mRNA), analysis type (cancer vs. normal analysis) and gene (CBX3).

Patients and tissue samples. A total of 98 osteosarcoma patients (56 males and 42 females; mean age, 18 years) who underwent initial surgery at the First Affiliated Hospital of Xinxiang Medical University (Xinxiang, China) between January 2008 and December 2017 were enrolled in this study. All patients were diagnosed with osteosarcoma at the Pathology Department of the First Affiliated Hospital of Xinxiang Medical University. Written informed consent for the participation in this study was obtained from all the patients. The Medical Ethics Committee of the First Affiliated Hospital of Xinxiang Medical University approved the use of the samples. All specimens were immediately frozen and stored in liquid nitrogen $\left(-196^{\circ} \mathrm{C}\right)$. Every patient was treatment-naïve until the resection.

Cell lines. The human osteosarcoma cell line MG63 was purchased from the Shanghai Cell Bank (Shanghai, China). Dulbecco's modified Eagle's medium (DMEM; Gibco; Thermo Fisher Scientific, Inc., Waltham, MA, USA) and 10\% fetal bovine serum (FBS; Invitrogen; Thermo Fisher Scientific, Inc.) were used to culture all the cells at $37^{\circ} \mathrm{C}$ in $5 \% \mathrm{CO}_{2}$.

Reverse transcription-quantitative polymerase chain reaction (RT-qPCR) assay. TRIzol was used to extract all the RNA from the osteosarcoma cells and tissues according to the manufacturer's protocol (Shanghai Invitrogen Biotechnology Co., Ltd., Shanghai, China). The qPCR was used to detect the expression levels of CBX3 mRNA by One-Step RT-PCR kit (Takara Bio, Inc., Otsu, Japan) based on the manufacturer's protocol. The thermocycling conditions were as follows: Initial denaturation at $95^{\circ} \mathrm{C}$ for $30 \mathrm{sec}$, followed by 40 amplification cycles of $95^{\circ} \mathrm{C}$ for $5 \mathrm{sec}$ and $60^{\circ} \mathrm{C}$ for $34 \mathrm{sec}$. The CBX3 primers were purchased from Shanghai Genechem Co., Ltd. (Shanghai, China). The internal reference was glyceraldehyde 3-phosphate dehydrogenase (GAPDH).
The primers used in the present study were as follows: CBX3 forward, 5'-TGGCCTCCAACAAAACTACA-3' and reverse, 5'-TCCCATTCACTACACGTCGA-3'; and GAPDH forward, 5'-GGAGTCAACGGATTTGGTCGTAT-3' and reverse, 5'-AGCCTTCTCCATGGTGGTGAAGAC-3'. The $2^{-\Delta \Delta \mathrm{Cq}}$ method (10) was used to quantify the CBX3 mRNA expression levels. Then, the GAPDH mRNA expression level was used to normalize it.

Transfection of osteosarcoma MG63 cells. The negative control siRNA (NC siRNA) and CBX3 small interfering RNA (siRNA) were provided by Shanghai GeneChem Biotechnology Co., Ltd. (Shanghai, China). The sequences of the siRNAs used in the present study were: Si-CBX3, 5'-GCG TTTCTTAACTCTCAGAAA-3' and negative control (NC), 5'-TTCTCCGAACGTGTCACGT-3'. The cells were cultured to $60 \%$ confluence, and were then plated in a 6-well plate at the density of $5 \times 10^{5} /$ well. The cells were then transfected with $50 \mathrm{nM}$ NC siRNA or CBX3 siRNA. Transfection was performed using Lipofectamine 2000 (Invitrogen; Thermo Fisher Scientific, Inc.) according to the manufacturer's protocol. qPCR and western blotting were used to validate the transfection efficiency of CBX3 siRNA $48 \mathrm{~h}$ after transfection.

Western blot analysis. The cells and tissues were harvested according to the manufacturer's instructions. A BCA protein assay kit (Pierce; Thermo Fisher Scientific, Inc.) was used to determine the protein concentration. Afterwards, equal amounts of total protein (50 $\mu \mathrm{g} /$ lane) were separated by $12.5 \%$ SDS-PAGE, and transferred onto polyvinylidene difluoride membranes. Membranes were blocked with 5\% skim milk powder in TBS-Tween $(0.1 \%)$ for $2 \mathrm{~h}$ at room temperature and then incubated with a 1:800 dilution of rabbit anti-CBX3 (cat. no. ab10480) antibody or a 1:2,500 dilution of rabbit anti-GAPDH (cat. no. ab9485) antibody (Abcam, Cambridge, MA, USA). Additionally, the secondary antibody was horseradish peroxidase-conjugated goat anti-rabbit IgG (1:10,000; cat. no. ab6721; Abcam). The positive bands were detected using the Enhanced Chemiluminescence plus western blotting detection system (GE Healthcare, Chicago, IL, USA). Band intensities were quantified by densitometry using ImageJ Software version 1.6 (National Institutes of Health, Bethesda, MD, USA). GAPDH was applied as the internal reference for the normalization of the expression levels of CBX3.

Cell proliferation assay and flow cytometry. After being transfected with NC siRNA or CBX3 siRNA, the cells at the exponential phase were cultured in 96-wells at a density of $4 \times 10^{3}$ cells/well. The Cell-Counting Kit-8 (CCK-8; Beijing Transgen Biotech Co., Ltd., Beijing, China) was used to determine the cell proliferation ability according to the manufacturer's instructions.

In addition, the MG63 cells were transfected with $\mathrm{NC}$ siRNA or CBX3 siRNA and incubated at $37^{\circ} \mathrm{C}$ for $48 \mathrm{~h}$. Afterwards, the transfected osteosarcoma cells were harvested and washed twice with phosphate-buffered saline (PBS). Then, $75 \%$ ice-cold ethanol was used for the fixation. Afterwards, there was management of the cells via the Cell Cycle Staining kit (Multi Sciences Biotech Co., Ltd., Hangzhou, China). The MG63 cells were harvested and incubated at room temperature 

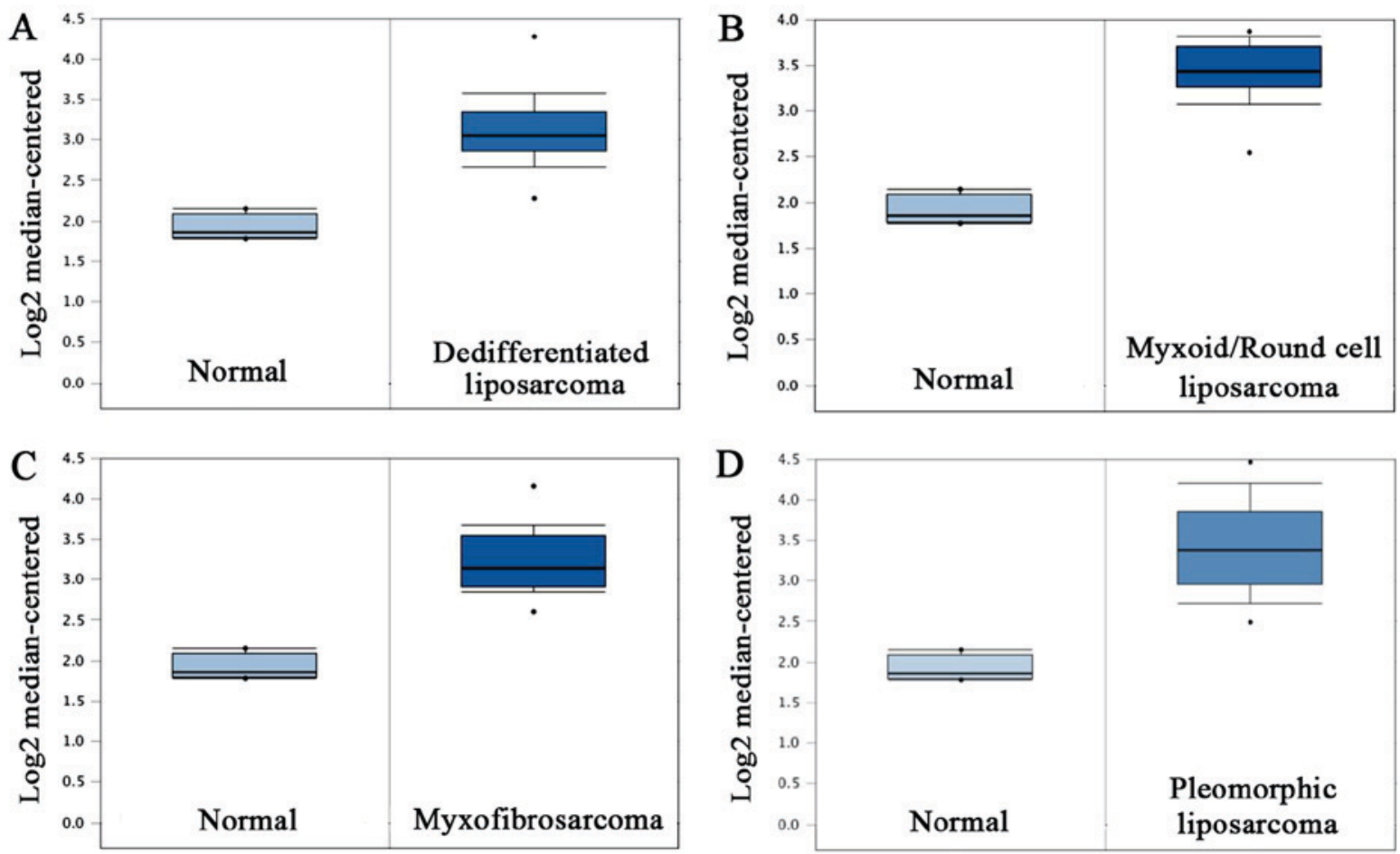

Figure 1.CBX3 is overexpressed in sarcoma tissues. CBX3 mRNA expression is significantly upregulated in (A) dedifferentiated liposarcoma,(B) myxoid/round cell liposarcoma, (C) myxofibrosarcoma and (D) pleomorphic liposarcoma compared with that in paired normal tissues. Data were collected and analyzed via the Oncomine database. CBX3, chromobox protein homolog 3.

for 15 min with FITC-conjugated Annexin V and propidium iodide (PI) to determine the impact of CBX3 siRNA on cell apoptosis according to the manufacturer's instructions (Annexin V-FITC Apoptosis Detection Kit; Nanjing KeyGen Biotech Co., Ltd., Nanjing, China). Flow cytometry was performed using a FACScan flow cytometer and the data were analyzed using the BD CellQuest software (version 5.1; BD Biosciences, San Jose, CA, USA).

Statistical analysis. The SPSS 22.0 software (IBM Corp., Armonk, NY, USA) was applied for the processing of the data and also for the statistical analysis. The data values are expressed as mean \pm standard deviation (SD). The Chi-square test was used to analyze the enumeration data. The Student's t-test was used for the analysis of the measurement data between two groups. The one-way analysis of variance (ANOVA) was used for group comparisons. Kaplan-Meier analysis was used to evaluate the survival. The log-rank test was used to compare the differences in the survival rates. In addition, the multivariate and univariate analysis applied the Cox regression analysis. Statistical significance was set at a P-value of $<0.05$.

\section{Results}

$C B X 3$ is overexpressed in human sarcoma tissues. To ascertain whether CBX3 was expressed differentially between the sarcoma tissues and the matched sarcoma tissues, the Oncomine database was analyzed to examine the CBX3 mRNA expression levels. There were altogether 4 analyses satisfying the inclusion standards. The statistics of Barretina sarcoma was chosen because of the presence of the majority of the research subjects. No statistics concerning the function of osteosarcoma is currently available. However, it was revealed from the research that in comparison with the normal adipose tissues, there was markedly higher CBX3 mRNA expression level in other sarcoma types, such as pleomorphic liposarcoma $(\mathrm{t}=12.188, \mathrm{P}<0.001$; Fig. 1D), myxofibrosarcoma $(\mathrm{t}=15.331$, $\mathrm{P}<0.001$; Fig. 1C), myxoid/round cell liposarcoma ( $\mathrm{t}=15.989$, $\mathrm{P}<0.001$; Fig. 1B) and dedifferentiated liposarcoma $(\mathrm{t}=2.270$, $\mathrm{P}<0.001$; Fig. 1A).

CBX3 is upregulated in human osteosarcoma tissues. Afterwards, the qPCR assay was used for the detection of the CBX3 expression levels in 98 osteosarcoma samples and the corresponding non-carcinoma bone tissues. Generally, Table I summarizes the clinicopathological features of the osteosarcoma patients. As shown in Fig. 2, a significantly higher level of CBX3 mRNA was observed in the osteosarcoma tissues compared with the level in the matched adjacent bone tissues $(\mathrm{t}=19.21, \mathrm{P}<0.001)$. It was suggested from these findings that CBX3 may be involved in osteosarcoma progression.

Correlation of $C B X 3$ expression with clinicopathological characteristics in osteosarcoma. Based on the statistical analysis, osteosarcoma patients were classified into a low CBX3 expression group $(n=49)$ and a high CBX3 expression group $(n=49)$. Associations of CBX3 expression with the clinicopathological features were then analyzed. As shown in Table II, there was a strong association between CBX3 expression and distant metastasis $(\mathrm{P}=0.022)$, clinical stage $(\mathrm{P}<0.001)$ and tumor size $(\mathrm{P}=0.043)$, but not with recurrence ( $P>0.05)$, lymph node metastasis, response to chemotherapy, pathological differentiation, anatomic location, sex and age. Additionally, it was revealed from the Spearman correlation 
Table I. Clinicopathological characteristics and expression of CBX3 in the osteosarcoma patient samples.

\begin{tabular}{|c|c|}
\hline Characteristics & No of cases $(\%)$ \\
\hline \multicolumn{2}{|l|}{ Age (years) } \\
\hline$<20$ & $61(62.2)$ \\
\hline$\geq 20$ & $37(37.8)$ \\
\hline \multicolumn{2}{|l|}{$\operatorname{Sex}$} \\
\hline Male & $56(57.1)$ \\
\hline Female & $42(42.9)$ \\
\hline \multicolumn{2}{|l|}{ Tumor size $(\mathrm{cm})$} \\
\hline$<5$ & $48(49)$ \\
\hline$\geq 5$ & $50(51)$ \\
\hline \multicolumn{2}{|l|}{ Location } \\
\hline Upper limb bone & $36(36.7)$ \\
\hline Lower limb bone & $62(63.3)$ \\
\hline \multicolumn{2}{|l|}{ Clinical stage } \\
\hline $\mathrm{I} / \mathrm{II}$ & $39(39.8)$ \\
\hline III/IV & $59(60.2)$ \\
\hline \multicolumn{2}{|c|}{ Pathological differentiation } \\
\hline Well/Moderately & $45(45.9)$ \\
\hline Poor & $53(54.1)$ \\
\hline \multicolumn{2}{|c|}{ Response to chemotherapy } \\
\hline Good & $54(55.1)$ \\
\hline Poor & $44(44.9)$ \\
\hline \multicolumn{2}{|c|}{ Lymph node metastasis } \\
\hline Absence & $58(59.2)$ \\
\hline Presence & $40(40.8)$ \\
\hline \multicolumn{2}{|l|}{ Distant metastasis } \\
\hline Absence & $72(73.5)$ \\
\hline Presence & $26(26.5)$ \\
\hline \multicolumn{2}{|l|}{ Recurrence } \\
\hline Absence & $44(44.9)$ \\
\hline Presence & $54(55.1)$ \\
\hline \multicolumn{2}{|c|}{ Expression of CBX3 } \\
\hline Low expression & $49(50)$ \\
\hline High expression & $49(50)$ \\
\hline
\end{tabular}

CBX3, chromobox protein homolog 3 .

analysis (Table III) of the correlation between the clinicopathological features and CBX3 that there was a strong correlation among distant metastasis $(\mathrm{P}=0.022)$, clinical stage $(\mathrm{P}<0.0001)$ and tumor size $(\mathrm{P}=0.044)$.

High CBX3 expression is associated with poor prognosis in osteosarcoma. To investigate the prognostic value of CBX3 expression in osteosarcoma, long-rank test and Kaplan-Meier analysis were conducted. It was shown from the results that there was an association between high $\mathrm{CBX} 3$ expression and shorter OS ( $\mathrm{P}<0.0001$; Fig. 3A) and DFS (P=0.003; Fig. 3B) of the osteosarcoma patients compared with those with low CBX3 expression.

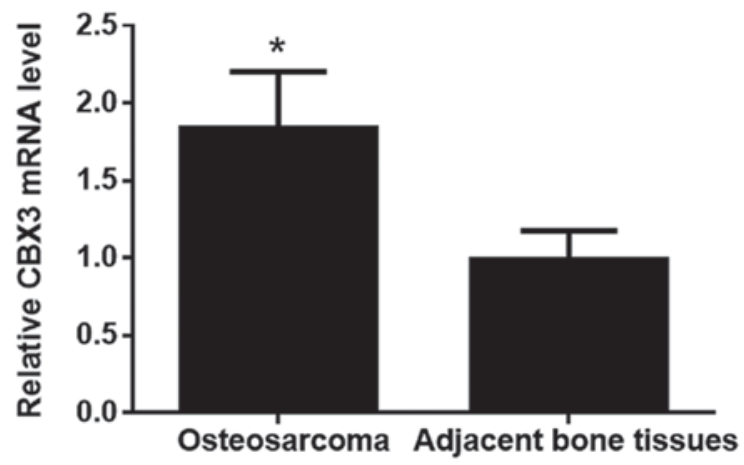

Figure 2. CBX3 expression level in osteosarcoma tissues was significantly higher than this level in corresponding non-cancerous bone tissues. " $\mathrm{P}<0.05$ compared with the paired adjacent bone tissues. CBX3, chromobox protein homolog 3 .

Afterwards, multivariate and univariate Cox regression was used for the collection and analysis of all the clinical data. It was demonstrated that CBX3 expression serves as an independent prognostic factor that could impact osteosarcoma patient OS (Table IV) and DFS (Table V).

CBX3 siRNA inhibits CBX3 expression in human osteosarcoma MG63 cells. To investigate the function of CBX3 in osteosarcoma, NC siRNA and CBX3 siRNA expressing GFP were transfected into human osteosarcoma MG63 cells. The qPCR and western blotting were used to analyze the knockdown efficiency. After the cells were transfected, the expression levels of CBX3 mRNA ( $\mathrm{t}=6.868, \mathrm{P}=0.0001$; Fig. 4B) and $\mathrm{CBX} 3$ protein $(\mathrm{t}=5.095, \mathrm{P}=0.0009$; Fig. $4 \mathrm{~A})$ in the MG63 cells of the CBX3 siRNA group were significantly lower compared with these levels in the NC siRNA group.

Downregulation of $C B X 3$ expression markedly inhibits the growth of osteosarcoma MG63 cells. To explore the impact of CBX3 on the growth of osteosarcoma cells, CCK-8 assay was conducted after osteosarcoma MG63 cells were transfected with NC siRNA or CBX3 siRNA. As shown in Fig. 4C, the proliferation rate of the MG63 cells was markedly inhibited by the knockdown of CBX3 expression in comparison with the NC siRNA group. Furthermore, on day $4(\mathrm{t}=4.612, \mathrm{P}=0.0017)$ and day $5(\mathrm{t}=8.017, \mathrm{P}<0.0001)$, there was an obvious reduction in the cell growth of the CBX3 siRNA group in vitro. Thus, CBX3 knockdown prevented the growth of osteosarcoma MG63.

Inhibition of CBX3 induces cell cycle arrestat G0/G1 phase and increases the apoptosis of osteosarcoma MG63 cells. There is a direct associated between proliferation and the distribution of the cell cycle. Therefore, we explored the cell cycle distribution of MG63 cells after CBX3 was downregulated. Flow cytometric analysis was used to assess the cell cycle in MG63 cells. As shown in Fig. 5A, the number of cells in the G0 and G1 phases had an increase of $14.60 \%(t=5.163, P=0.0067)$ in the CBX3 siRNA group while there was a decrease by $9.30 \%$ $(\mathrm{t}=8.664, \mathrm{P}=0.001)$ in the $\mathrm{S}$ phase and a decrease by $5.30 \%$ $(\mathrm{t}=4.743, \mathrm{P}=0.009)$ in the $\mathrm{G} 2 / \mathrm{M}$ phase following the knockout of CBX3. Moreover, the impact of CBX3 knockdown on the apoptosis of osteosarcoma MG63 cells was also explored. There was evidently higher percentage of apoptotic MG63 
Table II. Correlation between CBX3 expression and the clinicopathological characteristics of the osteosarcoma patients.

\begin{tabular}{|c|c|c|c|}
\hline \multirow[b]{2}{*}{ Characteristics } & \multicolumn{2}{|c|}{ CBX3 expression } & \multirow[b]{2}{*}{ P-value } \\
\hline & $\begin{array}{c}\text { Low } \\
(n=49)\end{array}$ & $\begin{array}{l}\text { High } \\
(n=49)\end{array}$ & \\
\hline \multicolumn{4}{|l|}{ Age (years) } \\
\hline$<20$ & 30 & 31 & 0.835 \\
\hline$\geq 20$ & 19 & 18 & \\
\hline \multicolumn{4}{|l|}{ Sex } \\
\hline Male & 30 & 26 & 0.414 \\
\hline Female & 19 & 23 & \\
\hline \multicolumn{4}{|l|}{ Tumor size (cm) } \\
\hline$<5$ & 29 & 19 & 0.043 \\
\hline$\geq 5$ & 20 & 30 & \\
\hline \multicolumn{4}{|l|}{ Location } \\
\hline Upper limb bone & 32 & 39 & 0.675 \\
\hline Lower limb bone & 17 & 19 & \\
\hline \multicolumn{4}{|l|}{ Clinical stage } \\
\hline $\mathrm{I} / \mathrm{II}$ & 29 & 10 & $<0.0001$ \\
\hline III/IV & 20 & 39 & \\
\hline \multicolumn{4}{|c|}{ Pathological differentiation } \\
\hline Well/Moderately & 22 & 23 & 0.839 \\
\hline Poor & 27 & 26 & \\
\hline \multicolumn{4}{|c|}{ Response to chemotherapy } \\
\hline Good & 31 & 23 & 0.104 \\
\hline Poor & 18 & 26 & \\
\hline \multicolumn{4}{|c|}{ Lymph node metastasis } \\
\hline Absence & 32 & 26 & 0.218 \\
\hline Presence & 17 & 23 & \\
\hline \multicolumn{4}{|l|}{ Distant metastasis } \\
\hline Absence & 41 & 31 & 0.022 \\
\hline Presence & 8 & 18 & \\
\hline \multicolumn{4}{|l|}{ Recurrence } \\
\hline Absence & 23 & 21 & 0.685 \\
\hline Presence & 26 & 28 & \\
\hline
\end{tabular}

CBX3, chromobox protein homolog 3 .

cells in the CBX3 siRNA group in comparison with the NC siRNA group ( $t=7.834, \mathrm{P}=0.0014$; Fig. 5B).

The results demonstrated that knockdown of $\mathrm{CBX} 3$ expression can suppress the proliferation of MG63 cells via the increase in the proportion of cells in the G0 and G1 phases of the cell cycle and a decrease in the percentage of cells during the $\mathrm{G} 2 / \mathrm{M}$ and $\mathrm{S}$ phases. In addition, knockdown of CBX3 expression induced apoptosis.

\section{Discussion}

The conserved chromatin binding proteins comprising the heterochomatin protein 1 (HP1) family, are directly associated with the methylated $\mathrm{H} 3 \mathrm{~K} 9$ (the methyl groups of histone $\mathrm{H} 3$
Table III. Spearman analysis of the correlation between CBX3 expression and clinicopathological characteristics of the osteosarcoma patients.

\begin{tabular}{lcc}
\hline Characteristics & Spearman correlation & P-value \\
\hline Age & -0.21 & 0.837 \\
Sex & 0.082 & 0.419 \\
Tumor size & 0.204 & 0.044 \\
Location & 0.042 & 0.679 \\
Clinical stage & 0.396 & $<0.001$ \\
Pathological differentiation & -0.02 & 0.841 \\
Response to chemotherapy & 0.164 & 0.106 \\
Lymph node metastasis & 0.125 & 0.222 \\
Distant metastasis & 0.231 & 0.022 \\
Recurrence & 0.041 & 0.688 \\
\hline
\end{tabular}

CBX3, chromobox protein homolog 3 .

at lysine 9) promoter region, and therefore, take part in the heterochromatin silencing of gene expression (7). The aberrant expression of HP1 can result in different human diseases, such as organism defects and cancer progression (11). Generally, chromobox protein homolog 3 (CBX3)-encoded heterochromatin protein $1 \gamma(\mathrm{HP} 1 \gamma)$ is a paralog of HP1.

High CBX3 expression has been reported in various types of cancers. CBX3 may be involved in the progression of cancer. Therefore, it is a potential cancer treatment target (12). Fan et al reported that colon cancer cell proliferation can be improved by targeting p21 and CDK6 in colorectal cancer (CRC) (6). Chang and colleagues found that CBX3 is overexpressed in non-small cell lung cancer (NSCLC) (13). Thus, it was hypothesized that CBX3 expression is a predictor of poor prognosis of patients suffering from NSCLC. Slezak et al (14) found a positive correlation between $\mathrm{Ki}-67$ expression and the CBX3 expression level, which could predict an unfavorable prognosis of prostate cancer patients. However, the function of CBX3 in the prognosis and progression of osteosarcoma has not yet been fully demonstrated.

Firstly, the present study investigated the function and also the clinical significance of CBX3 in osteosarcoma patients via the clinical data of osteosarcoma patients and public expression profiles. The results showed that the expression levels of CBX3 were significantly upregulated in sarcoma tissues in comparison with those in the normal adipose tissues. Then, high expression of CBX3 was noted in human osteosarcoma tissues in comparison with the corresponding adjacent bone tissues. Third, it was indicated from the statistical analysis that there was an evident correlation between CBX3 expression levels and a high distant metastasis rate, high clinical stage and a larger tumor size. It was confirmed by further univariate and multivariate analyses that $\mathrm{CBX} 3$ can be used as a potential prognostic biomarker for osteosarcoma patient.

Additionally, the CBX3 siRNA was designed and used for the transfection of MG63 cells in order to detect whether the cell cycle distribution, apoptosis and proliferation of the osteosarcoma cells can be impacted by downregulation of the gene expression levels of CBX3 in vitro. It was shown that 
Table IV. Univariate and multivariate analyses for overall survival in the osteosarcoma patients.

\begin{tabular}{|c|c|c|c|c|c|c|}
\hline \multirow[b]{2}{*}{ Variables } & \multicolumn{3}{|c|}{ Univariate analysis } & \multicolumn{3}{|c|}{ Multivariate analysis } \\
\hline & HR & $95 \% \mathrm{CI}$ & P-value & HR & $95 \% \mathrm{CI}$ & P-value \\
\hline Age & 0.784 & $(0.422-1.458)$ & 0.443 & 0.834 & $(0.408-1.706)$ & 0.619 \\
\hline Sex & 1.405 & $(0.769-2.566)$ & 0.268 & 0.758 & $(0.353-1.627)$ & 0.477 \\
\hline Tumor size & 1.114 & $(0.614-2.021)$ & 0.723 & 3.099 & $(1.406-6.833)$ & 0.005 \\
\hline Location & 0.858 & $(0.458-1.608)$ & 0.632 & 0.876 & $(0.402-1.913)$ & 0.741 \\
\hline Clinical stage & 1.512 & $(0.821-2.786)$ & 0.184 & 1.134 & $(0.519-2.478)$ & 0.753 \\
\hline Pathological differentiation & 0.849 & $(0.464-1.553)$ & 0.594 & 1.042 & $(0.536-2.024)$ & 0.904 \\
\hline Response to chemotherapy & 1.101 & $(0.600-2.022)$ & 0.756 & 0.53 & $(0.242-1.158)$ & 0.111 \\
\hline Lymph node metastasis & 2.288 & $(1.234-4.243)$ & 0.009 & 2.249 & $(1.147-4.407)$ & 0.018 \\
\hline Distant metastasis & 2.006 & $(1.011-3.982)$ & 0.046 & 1.562 & $(0.694-3.517)$ & 0.281 \\
\hline Recurrence & 15.06 & $(3.601-62.989)$ & $<0.001$ & 27.656 & $(6.089-125.616)$ & $<0.001$ \\
\hline Expression of $\mathrm{CBX} 3$ & 3.534 & $(1.808-6.909)$ & $<0.001$ & 4.259 & $(1.878-9.660)$ & 0.001 \\
\hline
\end{tabular}

CBX3, chromobox protein homolog 3; CI, confidence interval.

Table V. Univariate and multivariate analyses for disease-free survival in osteosarcoma patients.

\begin{tabular}{|c|c|c|c|c|c|c|}
\hline \multirow[b]{2}{*}{ Variables } & \multicolumn{3}{|c|}{ Univariate analysis } & \multicolumn{3}{|c|}{ Multivariate analysis } \\
\hline & HR & $95 \% \mathrm{CI}$ & P-value & HR & $95 \% \mathrm{CI}$ & P-value \\
\hline Age & 0.77 & $(0.440-1.348)$ & 0.360 & 0.743 & $(0.409-1.349)$ & 0.329 \\
\hline Sex & 1.434 & $(0.839-2.450)$ & 0.188 & 1.624 & $(0.890-2.962)$ & 0.114 \\
\hline Tumor size & 0.785 & $(0.457-1.345)$ & 0.378 & 0.61 & $(0.323-1.150)$ & 0.127 \\
\hline Location & 0.573 & $(0.573-1.734)$ & 0.996 & 0.863 & $(0.452-1.647)$ & 0.655 \\
\hline Clinical stage & 1.372 & $(0.793-2.377)$ & 0.258 & 1.365 & $(0.704-2.645)$ & 0.257 \\
\hline Pathological differentiation & 0.851 & $(0.495-1.465)$ & 0.561 & 0.683 & $(0.373-1.250)$ & 0.216 \\
\hline Response to chemotherapy & 1.305 & $(0.763-2.230)$ & 0.331 & 1.156 & $(0.628-2.127)$ & 0.641 \\
\hline Lymph node metastasis & 1.626 & $(0.926-2.857)$ & 0.091 & 1.452 & $(0.795-2.651)$ & 0.225 \\
\hline Distant metastasis & 1.68 & $(0.922-3.061)$ & 0.090 & 1.327 & $(0.647-2.723)$ & 0.441 \\
\hline Expression of CBX3 & 2.257 & $(1.291-3.946)$ & 0.004 & 1.902 & $(1.007-3.591)$ & 0.048 \\
\hline
\end{tabular}

CBX3, chromobox protein homolog 3; CI, confidence interval.
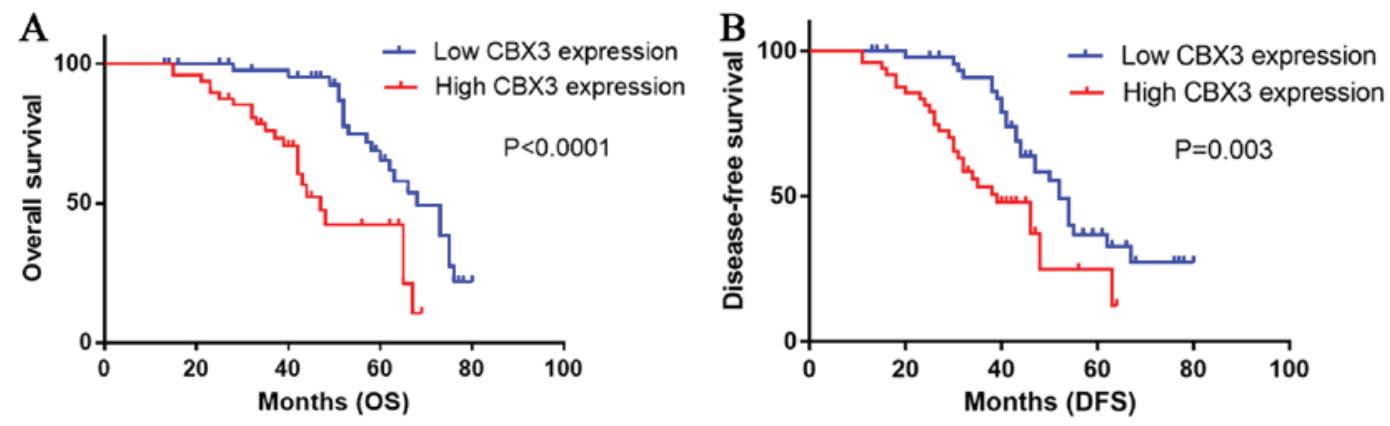

Figure 3. Kaplan-Meier curves showing the survival of osteosarcoma patients with high and low CBX3 expression levels. (A) OS curves stratified by CBX3 expression in osteosarcoma patients. (B) DFS curves stratified by CBX3 expression in osteosarcoma patients. CBX3, chromobox protein homolog 3 . OS, overall survival; DFS, disease-free survival.

the proliferation of MG63 cells was significantly prohibited by the knockdown of CBX3 expression via the increase in the percentage of cells during the G0 and G1 phases and a decrease in the proportion of the cells in the G2/M and $\mathrm{S}$ phases. In 
A
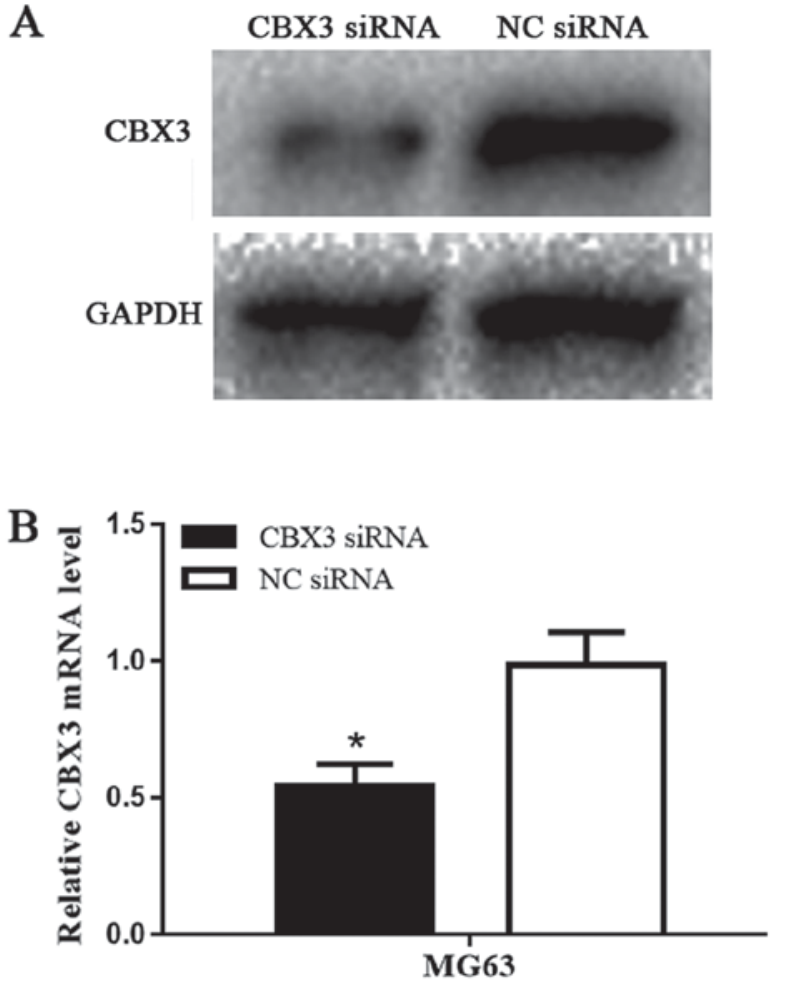
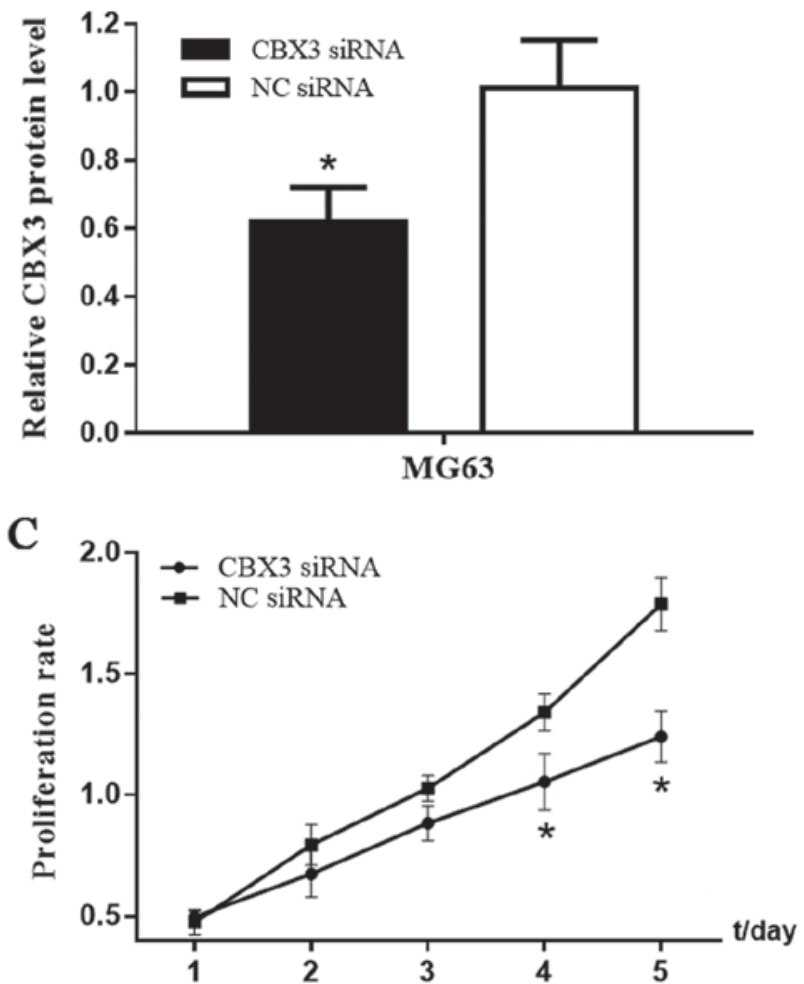

Figure 4. CBX3 siRNA was constructed to inhibit the proliferation of osteosarcoma cells. The knockdown efficiency of CBX3 was assessed by (A) western blotting and (B) qPCR assay, respectively. (C) CCK-8 assay shows that knockdown of CBX3 by CBX3 siRNA decreased the proliferation of osteosarcoma MG63 cells when compared to the NC siRNA group. ${ }^{*} \mathrm{P}<0.05$ compared with the NC siRNA group. CBX3, chromobox protein homolog 3 ; CCK-8, Cell-Counting Kit-8.
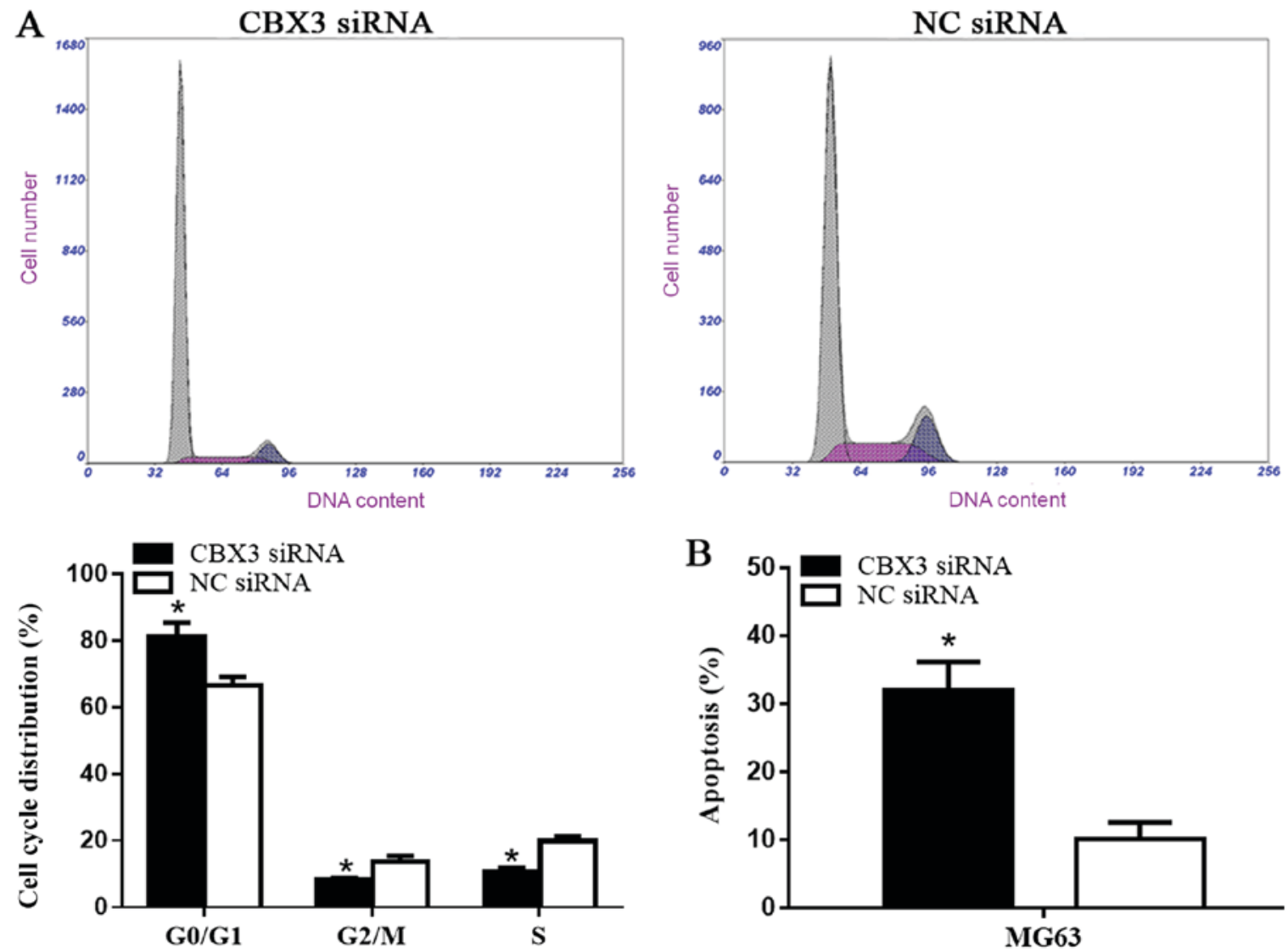

Figure 5. CBX3 modulates the cell cycle distribution and apoptosis of osteosarcoma MG63 cells. (A) Flow cytometric analysis of cell cycle distribution of the MG63 cells transfected with CBX3 siRNA or NC siRNA. (B) Flow cytometric analysis of the percentage of apoptotic MG63 cells transfected with CBX3 siRNA or NC siRNA. "P<0.05 compared with the NC siRNA group. CBX3, chromobox protein homolog 3. 
addition, apoptosis was induced. Nevertheless, further evaluation and validation must be further conducted to evaluate the function of CBX3 in cell lines of osteosarcoma and the explicit system implied by such association.

In conclusion, our findings demonstrated that CBX3 is of great significance in the prognosis and progression of human osteosarcoma. CBX3 is highly expressed in human osteosarcoma tissues. The dismal prognosis of patients suffering from osteosarcoma can be predicted by high CBX3 expression. In addition, the proliferation of osteosarcoma MG63 cells was inhibited following the downregulation of CBX3 expression. This was realized by induction of cell apoptosis and cell cycle arrest. Thus, CBX3 can be valuable as an independent potential prognostic biomarker for patients suffering from osteosarcoma.

\section{Acknowledgements}

Not applicable.

\section{Funding}

The present study was supported by The Youth Fund Project of the First Affiliated Hospital of Xinxiang Medical University (grant no. QN-2017-B018).

\section{Availability of data and materials}

The datasets used and/or analyzed during the current study are available from the corresponding author on reasonable request.

\section{Authors' contributions}

$\mathrm{CM}$ collected and analyzed the patient data and was a major contributor in writing the manuscript. CM, XGN and YLW performed the western blot and qPCR analyses. XHL, XL, QLZ and CM performed the cell culture, transfection and flow cytometric analysis. QLZ performed the statistical analysis. DPW contributed to the conception and design of the study and revised it critically for important intellectual content. All authors read and approved the manuscript and agree to be accountable for all aspects of the research in ensuring that the accuracy or integrity of any part of the work are appropriately investigated and resolved.

\section{Ethics approval and consent to participate}

The present study was performed according to the Declaration of Helsinki of 1964 and all subsequent revisions, and the Medical Ethics Committee of The First Affiliated Hospital of Xinxiang Medical University (Xinxiang, China) approved the use of the samples. Written informed consent for the participation in this study was obtained from all the patients.

\section{Patient consent for publication}

Informed consent was obtained from all patients.

\section{Competing interests}

The authors declare that they have no competing interests.

\section{References}

1. Zhang GY, Zhang JF, Hu XM, Luo ZP and Ma YZ: Clinical significance of long non-coding RNA EWSAT1 as a novel prognostic biomarker in osteosarcoma. Eur Rev Med Pharmacol Sci 21: 5337-5341, 2017.

2. Fan J, Mei J, Zhang MZ, Yuan F, Li SZ, Yu GR, Chen LH, Tang Q and Xian CJ: Clinicopathological significance of glucose transporter protein-1 overexpression in human osteosarcoma. Oncol Lett 14: 2439-2445, 2017.

3. Yoshida A, Fujiwara T, Uotani K, Morita T, Kiyono M, Yokoo S, Hasei J, Nakata E, Kunisada T and Ozaki T: Clinical and functional significance of intracellular and extracellular microRNA-25-3p in osteosarcoma. Acta Med Okayama 72: $165-174,2018$.

4. Longhi A, Errani C, De Paolis M, Mercuri M and Bacci G: Primary bone osteosarcoma in the pediatric age: State of the art. Cancer Treat Rev 32: 423-436, 2006.

5. Chou AJ, Geller DS and Gorlick R: Therapy for osteosarcoma: Where do we go from here? Paediatr Drugs 10: 315-327, 2008.

6. Fan Y, Li H, Liang X and Xiang Z: CBX3 promotes colon cancer cell proliferation by CDK6 kinase-independent function during cell cycle. Oncotarget 8: 19934-19946, 2017.

7. Canzio D, Larson A and Narlikar GJ: Mechanisms of functional promiscuity by HP1 proteins. Trends Cell Biol 24: 377-386, 2014

8. Esteller M: Cancer epigenomics: DNA methylomes and histone-modification maps. Nat Rev Genet 8: 286-298, 2007.

9. Chen LY, Cheng CS, Qu C, Wang P, Chen H, Meng ZQ and Chen Z: CBX3 promotes proliferation and regulates glycolysis via suppressing FBP1 in pancreatic cancer. Biochem Biophys Res Commun 500: 691-697, 2018.

10. Livak KJ and Schmittgen TD: Analysis of relative gene expression data using real-time quantitative PCR and the 2(-Delta Delta C(T)) method. Methods 25: 402-408, 2001.

11. Dialynas GK, Vitalini MW and Wallrath LL: Linking heterochromatin protein 1 (HP1) to cancer progression. Mutat Res 647: 13-20, 2008.

12. Zhang H, Chen W, Fu X, Su X and Yang A: CBX3 promotes tumor proliferation by regulating $\mathrm{G} 1 / \mathrm{S}$ phase via $\mathrm{p} 21$ downregulation and associates with poor prognosis in tongue squamous cell carcinoma. Gene 654: 49-56, 2018.

13. Chang SC, Lai YC, Chen YC, Wang NK, Wang WS and Lai JI: $\mathrm{CBX} 3$ /heterochromatin protein 1 gamma is significantly upregulated in patients with non-small cell lung cancer. Asia Pac J Clin Oncol: Nov 10, 2017 (Epub ahead of print). doi: 10.1111/ajco.12820.

14. Slezak J, Truong M, Huang W and Jarrard D: HP1 $\gamma$ expression is elevated in prostate cancer and is superior to Gleason score as a predictor of biochemical recurrence after radical prostatectomy. BMC Cancer 13: 148, 2013.

(i) $($ ) This work is licensed under a Creative Commons Attribution-NonCommercial-NoDerivatives 4.0 International (CC BY-NC-ND 4.0) License. 